Por Iván René León Garzón*

\title{
LA RELACIÓN DE LOS JÓVENES CON LOS CÓMICS A TRAVÉS DEL TIEMPO
}

a constante necesidad de explorar nuevos mundos por parte de los jóvenes hace que las manifestaciones narrativas puedan alcanzar la cúspide de su crecimiento. A lo que normalmente se le da el nombre de entretenimiento configura la naturaleza de un motor que activa la evolución sobre los procesos de la sociedad. Esa libertad que otorga el "ocio" es la que permite imaginar un mundo futuro y son los jóvenes los que se alimentan de esta libertad constructora y crean puentes entre la imaginacióny la realidad. La forma en que la "entretención en el tiempo libre" ha logrado crear nuevos dispositivos y hacer creer a los jóvenes nos ha proyectado como la sociedad contemporánea en la era digital o de la información en la que estamos ahora. Esta idea se plantea en el artículo de Gamero (2018) sobre la forma en que su lectura constante aporta a los jóvenes:

Esa libertad que otorga el

"ocio" es la que permite

imaginar un mundo

Los cómics no solo no están por debajo de futuro y son los jóvenes la literatura tradicional ni son una puerta infantil hacia ella sino que la maravillosa y compleja relación que se establece en este formato entre imágenes y palabras consigue hacer magia en nuestro cerebro.

\section{los que se alimentan de}

El reloj de pulsera que sirve a Dick Tracy para intercomunicarse se hizo popular esta libertad constructora

y crean puentes entre la

imaginación y la realidad. 
Figura 1. Comic Dick Tracy.

Nota: la imagen de la izquierda es

la portada creada por Gould en una entrega especial para coleccionistas de 1975 y la segunda imagen de la de recha página del cómic programado por Chester Gould para el 22 de enero de 1967 en donde se puede reconocer el uso del "telereloj". Fuente: Gould (1931, enero)
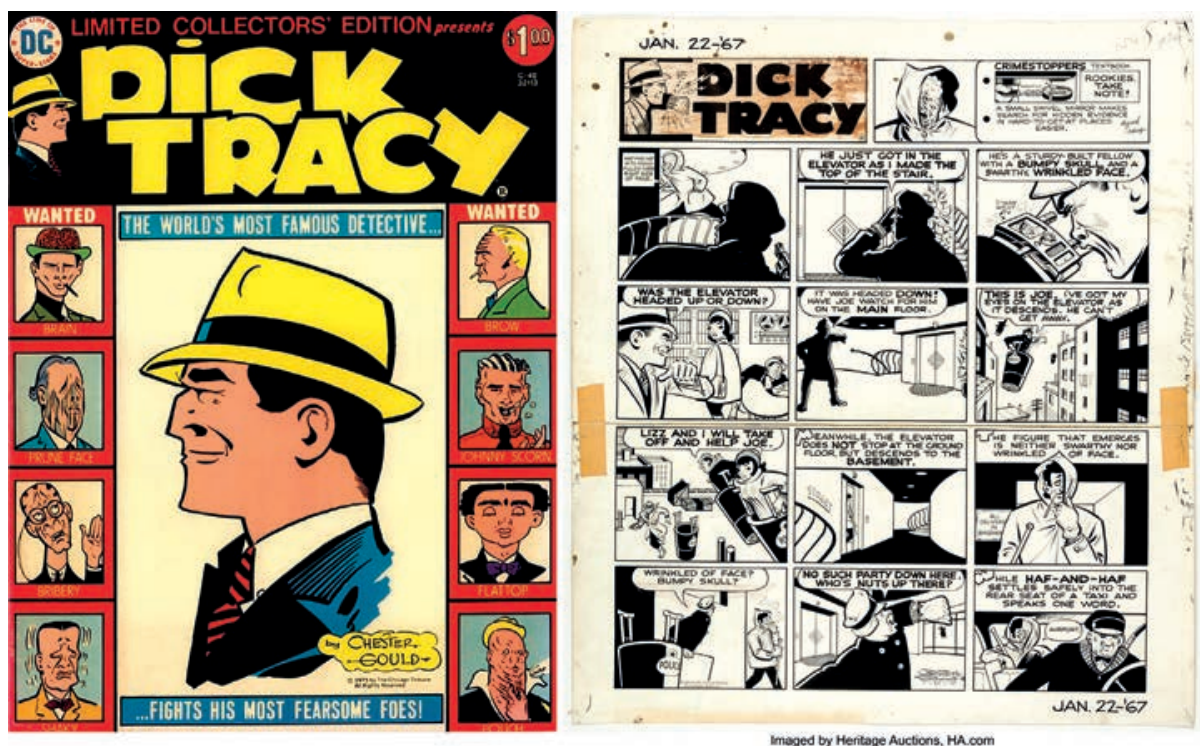

hace unos años (ver figura 1). Sin que sea su función principal, el cómic proyecta el pensamiento crítico sobre lo creado y lo que influye en la sociedad, por encima del término de diversión llega a la formación de un criterio personal. A este respecto también aporta el escritor Gene Luen Yang, creador de la novela gráfica American Born Chinese (2008), quien lo plantea de la siguiente manera en el portal Big Think:

[...] las imágenes solo eran una fiel representación del mensaje transmitido por las palabras. Si el mensaje decía “Superman golpea a Lex Luthor" en la imagen simplemente te encontrabas a Superman golpeando a Lex Luthor. Eso reforzaba la idea de que los cómics no eran para gente muy lectora: si no entendías las palabras siempre podías recurrir a la imagen. Ahora, en cambio, la relación entre palabras e imágenes se ha convertido un arte en símismo. Por ejemplo, en ocasiones la importancia recae en el texto y otras veces en la imagen, o puede ocurrir que ambos entren en contradicción y el lector deba decidir cuál es el verdadero. Y así sucesivamente.

\section{El joven del siglo $x \mathrm{x}$ se enfrenta a narrativas de la máquina social estadounidense}

Durante los años treinta comienza el florecimiento del cómic como constructor de historias, muy ligado a la estructura literaria del narrador, cuya voz escrita debe obligatoriamente acompañar cada acción desarrollada en todas las viñetas. El narrador omnisciente era invasivo, pues disponía las emociones y las actitudes desde la palabra, y eludía el recurso gráfico. En la figura 2 se puede comprobar esa intención de copiar características de la literatura y la multiplicidad de cuadros de diálogo que inundan la viñeta.

Esta saturación de contenidos dados por el narrador, seguramente heredado (como se ha dicho anteriormente) de la literatura, también tiene una conexión con la radio a través de la cual se ejecutaron narrativas ficcionales con la intensidad de la voz de un narrador de los eventos. 

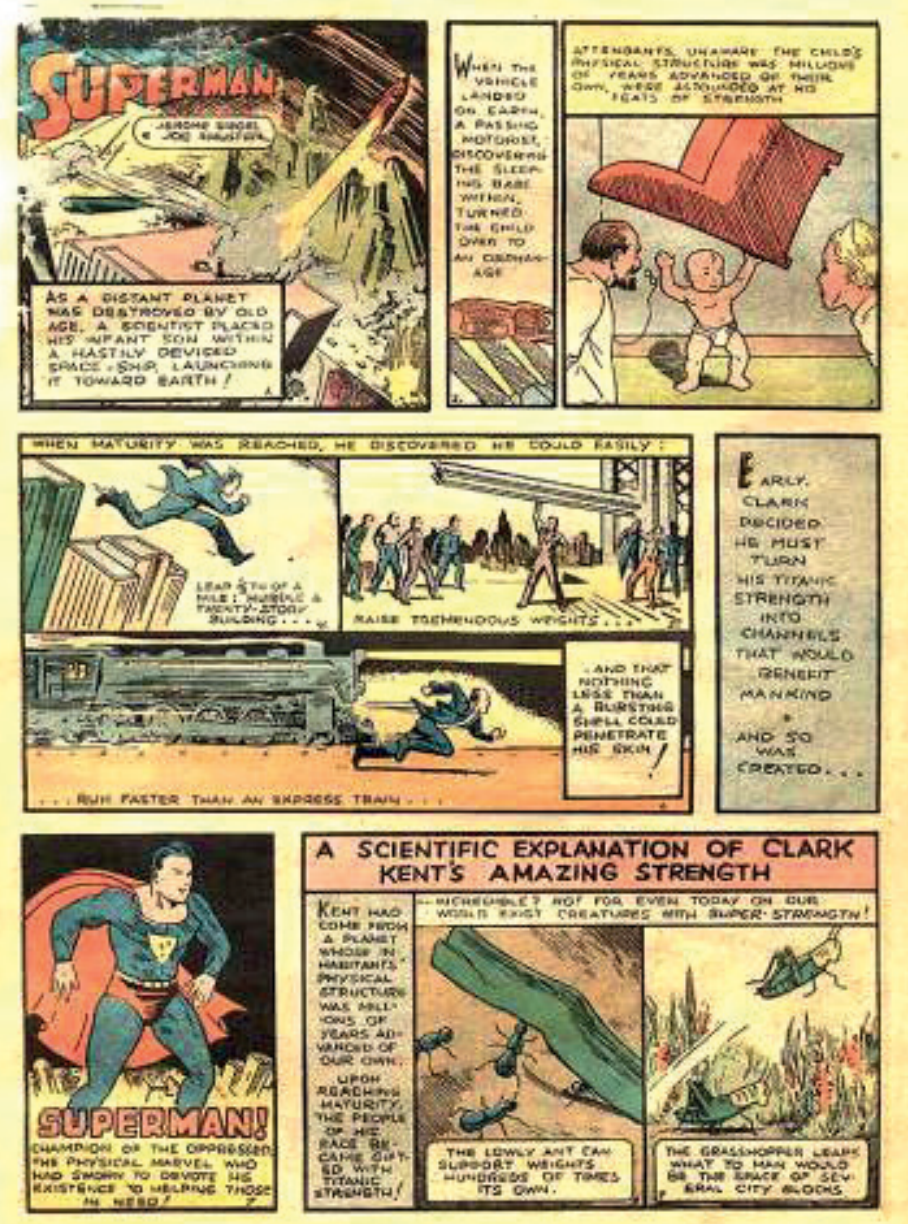

Figura 2. Primera página del primer cómic sobre superhéroes, el primero creado: Superman
Para la radio este recurso es coherente, no mucho para los cómics, aunque quienes comenzaron a leerlos, se familiarizaron sin dificultad con este tipo de estructura. Literatura y radio, dos medios de divulgación de historias con características específicas. La primera permite la creación de imágenes mentales de los sucesos a través de la descripción escrita de ellos. La segunda ofrece la intensidad de las voces, la música, los efectos sonoros que ambientan las escenas. Obviamente esta descripción en los cómics a través de un narrador es heredada de la literatura y llevada a la emocionalidad de lo sonoro. Dentro del entretenimiento los temas desarrollados por la literatura eran densos, la radio ofrecía historias relacionadas a los adultos, aunque muchos jóvenes se sentían atraídos no era el tipo de historias que pudieran
El narrador omnisciente

era invasivo, pues disponía

las emociones y las

actitudes desde la palabra,

y eludía el recurso gráfico.

ser consumida normalmente por este público. Los jóvenes, un público creciente en una época acomodada a los adultos, logran crear un espacio que los toca, los interesa y los vuelve depredadores de contenidos.

Hacia los años sesenta las narrativas no parecen cambiar demasiado. Sigue el narrador siendo el gran integrador de los eventos, las emociones de los personajes, las circunstancias que influyen en las acciones. Se refina mucho más el dibujo y la organización de la historia se vuelve mucho más eficiente a través de las viñetas. Por ejemplo, en la figura $\mathbf{3}$ se puede verificar la ilustración mucho más elaborada:

¿Contra qué compite el cómic a nivel de entretención' En la misma página de Accion Comic $n^{\circ} 1$ se puede reconocer un elemento que se masificó durante la década en que se publicó el cómic, la televisión. Sin embargo, el cómic continua vigente porque su público no ha sido aún cubierto por la parrilla que se exponía en esa época en la televisión. Los jóvenes todavía se identifican con esta manera de narración y mucho más con la expresividad que ofrece el cómic en su evolución. El mismo tema de la carrera nació al escuchar lo que su público quería ver en sus páginas.

En los años ochenta el narrador prácticamente desapareció. La competencia de laimagen fija versus la imagen en movimiento adquiría un nuevo matiz. La televisión comienza a crear contenidos para jóvenes y captura de lleno 
Figura 3. Superman 199, "Superman's Race With the Flash".

Fuente: Shooter y Swan (1967). su atención. Dentro del universo del cómic, se aprovechó mucho la narrativa construida décadas atrás para desarrollar animaciones que expandíansuuniverso narrativo. A continuación, en la figura 4 se reconoce la nueva manera de narrar del cómic:
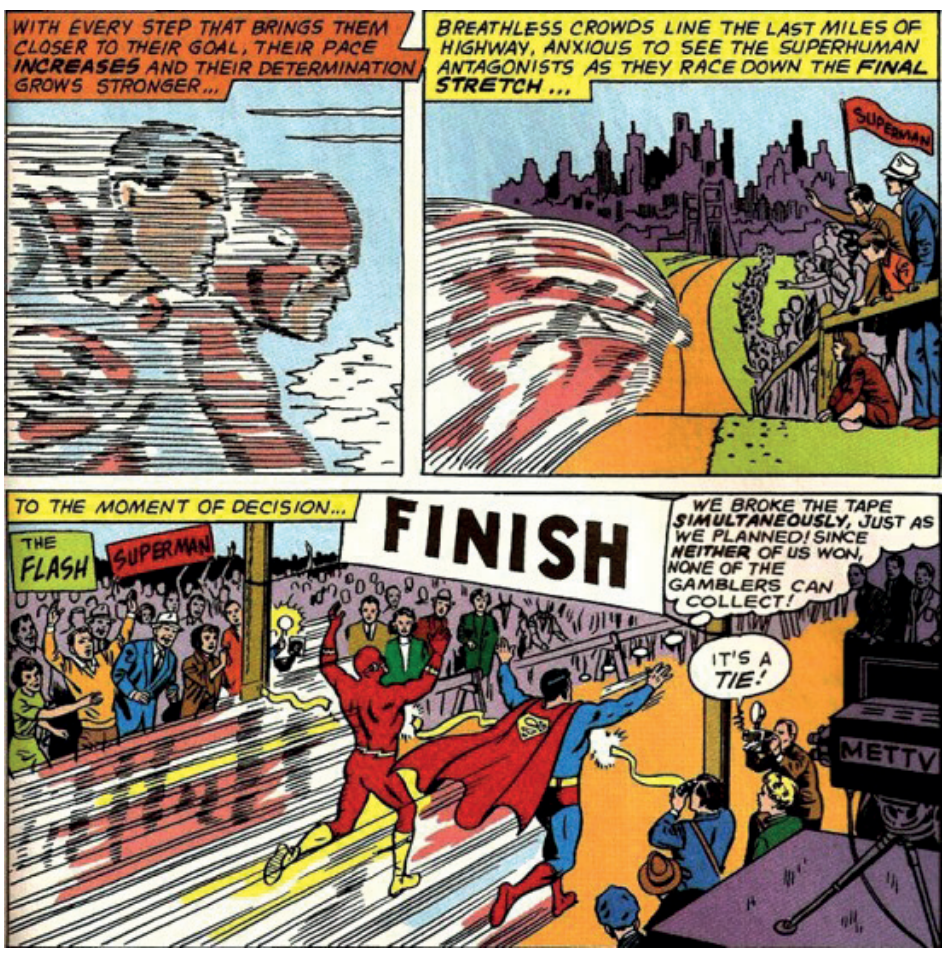

Respecto a los números sobre Supermán publicados en los años sesenta, se lograron manejar muchos más colores, lo que otorgó una gráfica atractiva al ojo del lector. La distribución de los espacios dentro de las viñetas fue mucho más eficiente y contribuyó en la narración principal. Las historias desarrolladas seguían siendo novedosas y atrapaban al público ferviente que las seguía. El colapso se veía venir, la diversificación de narraciones en diferentes formatos también dividía a sus lectores y los convertía en telespectadores asiduos, obnubilados por el movimiento. Afortunadamente no fue el fin.
Figura 4. Superman: ¿Qué pasó con el hombre
del mañana?
Nota: La acción la determina la imagen, no el
narrador. Las emociones están en las expresiones de
sus personajes y no requiere una interpretación en
texto adicional en la viñeta.
Fuente: Moorey Swan (1986, septiembre). 


\section{El contacto de los jóvenes con el cómic en tiempos contemporáneos}

El joven de la generación Z, durante las últimas dos décadas, fue llevado desde el cine hacia el cómic, al cual ve como una manifestación histórica de la narrativa. Las historias épicas narradas en el cine, la creación de las historias individuales y su mitología determinan una búsqueda arqueológica en la web

\section{Los videojuegos también}

se establecen como

dispositivos narradores

de historias, muchas de

ellas llevadas al cine y al

cómic. La estética de los

videojuegos también es

parte de construcción

del mundo de ficción

de los jóvenes. para reconstruiry recomponer el rompecabezas que conecta la narrativa cinematográfica. Este puede determinarse como elpunto de acercamiento del joven a la narrativa del cómic. Sin embargo no es el único. Dentro del espacio académico electivo llamado narrativa del cómic, que convoca a jóvenes de diferentes facultades de la Universidad Santo Tomás se puede comprobar que hay una búsqueda importante en el estilo de narración de diferentes culturas a nivel mundial.
Otra ruta de acercamiento ha sido el anime japonés. Muchos de los jóvenes que llegan a la electiva alguna vez en sus vidas se denominaron Otaku, tribu urbana de jóvenes fuertemente ligados al anime y manga japonés; estos reconstruyen la mitología de las historias que se narran basadas en la cultura del samurái, del ninja o de las historias de terror basadas en las vidas en las ciudades y ruralidades niponas.

Los videojuegos también se establecen como dispositivos narradores de historias, muchas de ellas llevadas al cine y al cómic. La estética de los videojuegos también es parte de construcción del mundo de ficción de los jóvenes. En la figura 5 se pueden reconocer algunos de los videojuegos que aportaron a la concepción del mundo mágico de los centennials.

Los jóvenes centennials han sido altamente entrenados en el artilugio del dibujo animado. Grandes historias han construido su infancia, por ejemplo Las chicas superpoderosas, Coraje el perro cobarde, Samurái Jack, Las sombrías aventuras de Billyy Mandy, Mansión Foster para amigos imaginarios, Kim Possible, entre otros (ver figura 6).

\footnotetext{
Figura 5. Final Fantasy viI; Half-Life; Resident Evil 2; Metal Gear Solid; The Legend of Zelda: Ocarina on Time.

Nota: portada de videojuegos lanzados entre los años 1997 y 1998 en las consolas PlayStation y Super Nintendo.

Fuente: elaboración propia de la unión de "Portada Final Fantasy vir", "Portada Half-Life", "Portada Resident Evil z", "Portada Metal Gear Solid" y "Portada The Legend of Zelda: Ocarina on Time"
}

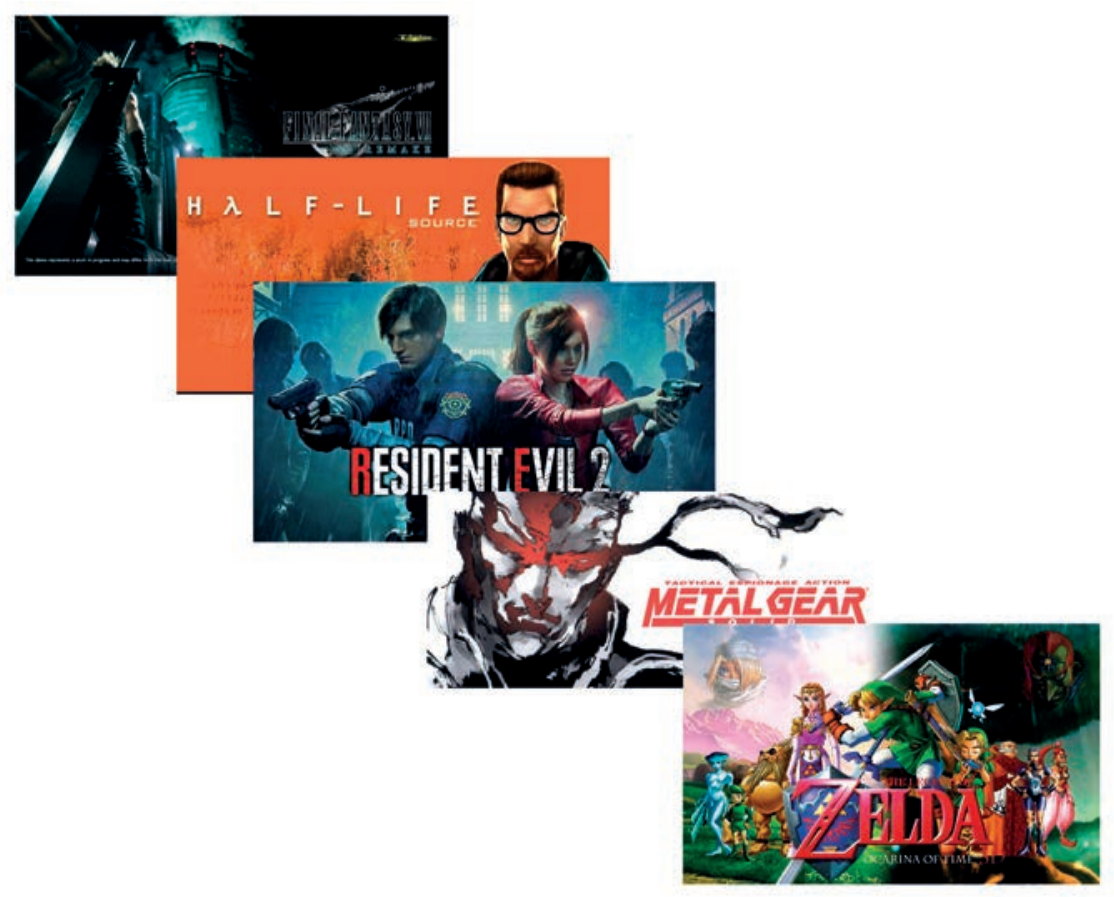




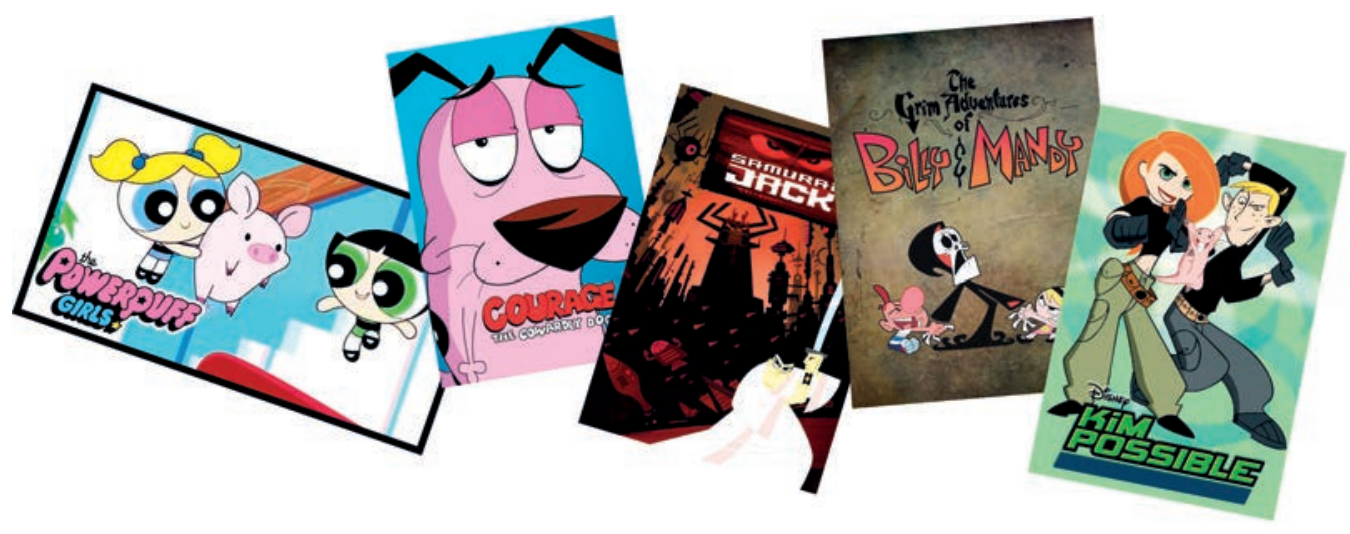

Figura 6. Las chicas superpoderosas, Coraje el perro cobarde, Samurái Jack, Las sombrías aventuras de Billyy Mandy, Mansión Foster para amigos imaginarios y Kim Possible. Fuente: elaboración propia de la unión de "Las chicas suporpoderosas", "Coraje el perro cobarde” Samurái Jack", "Las sombrías aventuras de Billy y Mandy" y "Kim Possible",

Para evidenciar esta influencia se debe que revisar la publicación de abril del 2006, el número 469 de la serie llamada The Adventures of Superman. En este número se puede observar el predominio estético determinado por la época. A continuación, en la figura 7, se puede observar el desarrollo de un trazo definido y fuerte, similar a lo que se observa en las series animadas:

Los altos contrastes entre los colores, semejantes al claro oscuro, recurso gráfico que aporta al dramatismo de la narrativa, se integra a las formas del cómic, mucho más definido, con un trazo fuerte y casi mecánico.

Lograr identificar el entorno que rodeó a los estudiantes durante su crecimiento aporta a la construcción de su imaginario cuando se trata de desarrollar historias en el curso de narrativas del cómic. Es importante contrastar los cambios en las prácticas de consumo de entretenimiento por parte de los jóvenes desde la creación de cómic hasta el momento actual para comprender la creación de sus propias narraciones.

\section{Construcción de la narrativa del joven a través del cómic}

Para este artículo, se han seleccionado algunos trabajos entregados por los estudiantes a lo largo dos años para evidenciar la influencia que contribuye en sus creaciones:

\section{Lograr identificar el entorno que rodeó a los}

\section{estudiantes durante su crecimiento aporta a}

la construcción de su imaginario cuando se

trata de desarrollar historias en el curso de

\section{narrativas del cómic.}

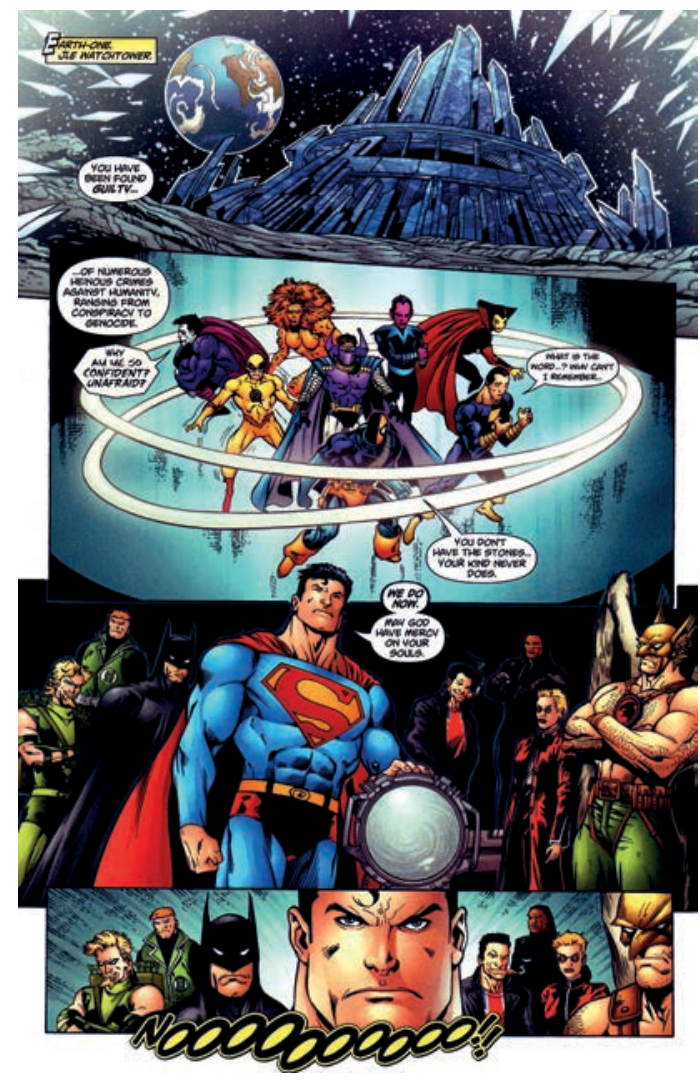

Figura 7. The Adventures of Superman, número 469. Fuente: Kelly et al. (2006, 06 de abril). 
Figura 8. Tyrius (2018-1).

Nota: proyecto Tyrius presentado durante el primer semestre de 2018 creado por el estudiante ya egresado Julián Alberto Galeano Vélez, de la Facultad de Diseño Gráfico. Fuente: Galeano Vélez (2018).

Figura 9. $\operatorname{Sin}$

nombre (2018-2)

Nota: Este proyecto cuyos autores Sebastián Arboleda Bernal, Joaquín Doncel Robayo y Santiago Rincón Rey, de la Facultad de Comunicación Social, prefirieron no darle nombre, fue presentado en el segundo periodo del año 2018.

Fuente: Arboleda Bernal et al. (2018).
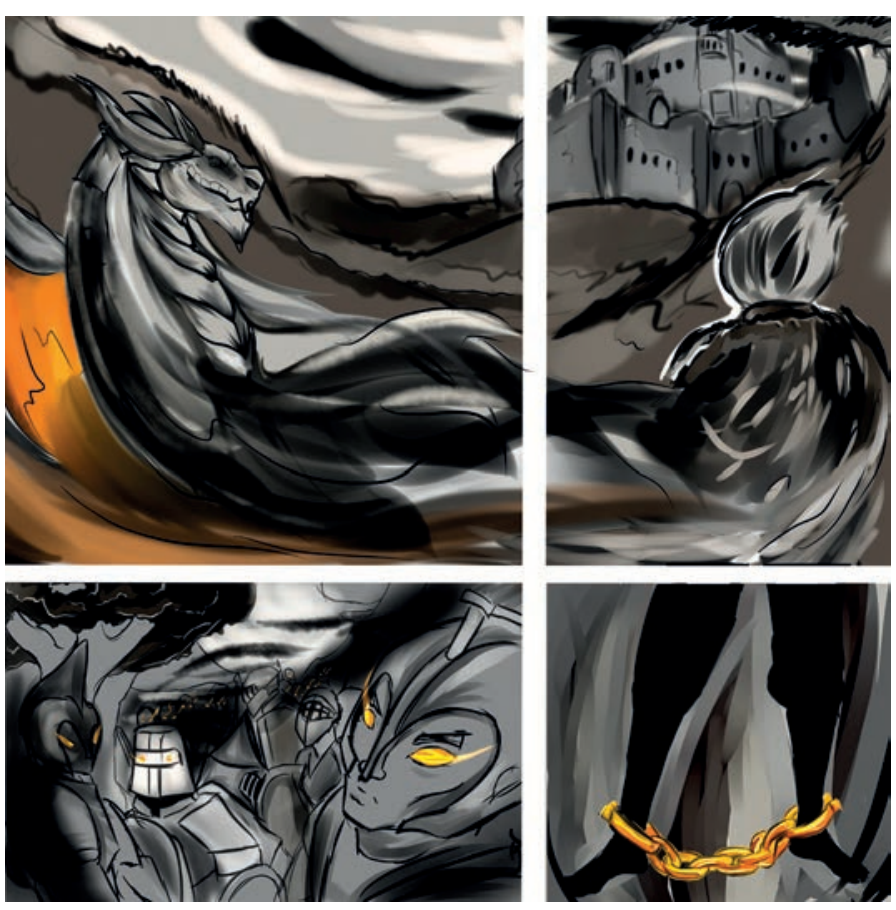

El dragón ha sido

una de las creaturas

mitologías que más

expresión ha tenido en

los cómics, tanto como

agente colaborador o

antagonista.
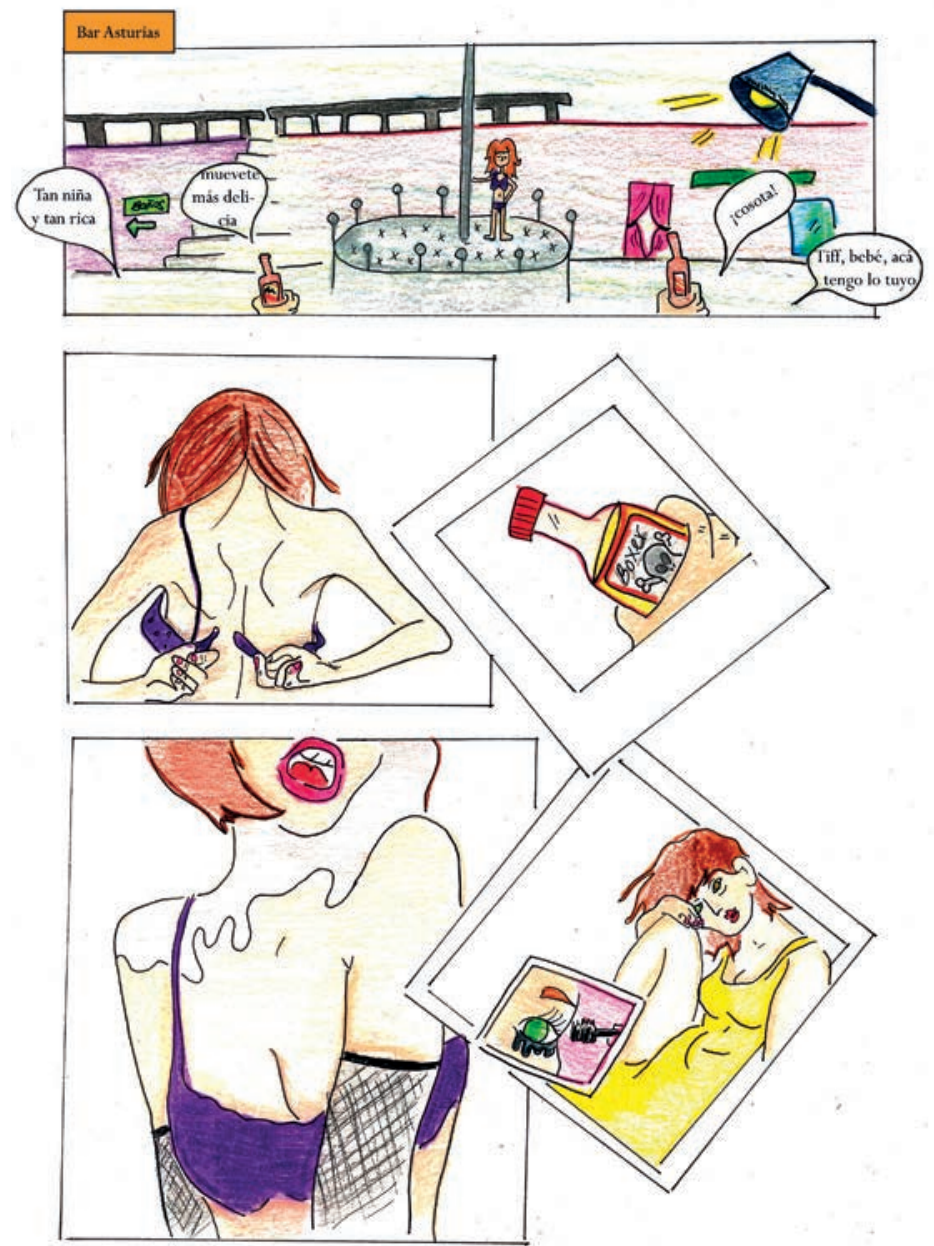

En el proyecto expuesto en la figura 8, el estudiante Julián Galeano explora la temática del dragón y lo vincula con el ser humano y sus necesidades, sus emociones y sus intereses. El dragón ha sido una de las creaturas mitologías que más expresión ha tenido en los cómics, tanto como agente colaborador o antagonista. En Tyrus, es el personaje principal y está integrado al ser humano por un efecto de mutación que determina el linaje y las jerarquías. Las fisonomías de los personajes son cercanas a las realizadas en el manga, pero con una temática más occidental como la monarquía y el control de grandes poderes. La mutación es parte de la narrativa del cómic norteamericano, como se puede constatar en los desarrollados por Marvel y los X-Men o Mutantes.

En el proyecto sin nombre (ver figura 9), los estudiantes Sebastián Arboleda, Joaquín Doncel y Santiago Rincón aprovecharon la información encontrada en su trabajo modular de semestre sobre la prostitución infantil. No es un tema recurrente en el cómic, sin embargo, se puede reconocercomoun mecanismo social parainformar al público joven. En el trabajo desarrollado 
por los estudiantes se reconoce la intención de los familiares de las jóvenes por venderlas para ser explotadas sexualmente por su proxeneta; muy ajustado a la información que ellos como investigadores encontraron en la comunidad estudiada. Los estudiantes decidieron hacer el ejercicio ilustrando sobre papel al tomar referencias de imágenes que podrían sumar a la viñetación preliminar. La disposición de los personajes sobre la viñeta determina, primero, el acoso al que se someten y, segundo, la sensación de soledad que se construye al vestirse y maquillarse.

Elproyecto Sevendeen la Coruña (2019-1) (ver figura 10) está suscrito en el género de terror, los autores presentan un personaje que viaja de Madrid, España, a la región de la Coruña y tiene que buscar un lugar para hospedarse. Los estudiantes se atrevieron a contar una historia en una ciudad lejana que no conocen. En este trabajo se ve una preocupación por mantener una estética y una coherencia en cada una de las viñetas. Se puede reconocer una fuerte influencia del manga en la última viñeta, en donde la sorpresa es exagerada, el rostro parece sombrío y la sensación de sentirse observado se representa con la metáfora visual de los múltiples ojos observantes e insidiosos. La tecnología es un punto importante en la ilustración de la página, el color dispuesto es realizado a través de un programa editor de fotografías para darle un toque de calidad al diseño final.

En la búsqueda deuna identidad en Colombia, los jóvenes creadores del proyecto Bachué, intentan hacer cotidiana y contemporánea la historia de Bochica y Bachué al agregarle misterio a la mitología muisca. En el proyecto lograron integrar la imagen fotográfica de la laguna de Guatavita como escenario del encuentro entre los personajes; estos aparecen ilustrados en tres colores, el blanco, el negro y el color amarillo para simbolizar su conexión al oro, que ha sido el metal principal en la narrativa de la leyenda de El Dorado en Colombia (ver figura 11).
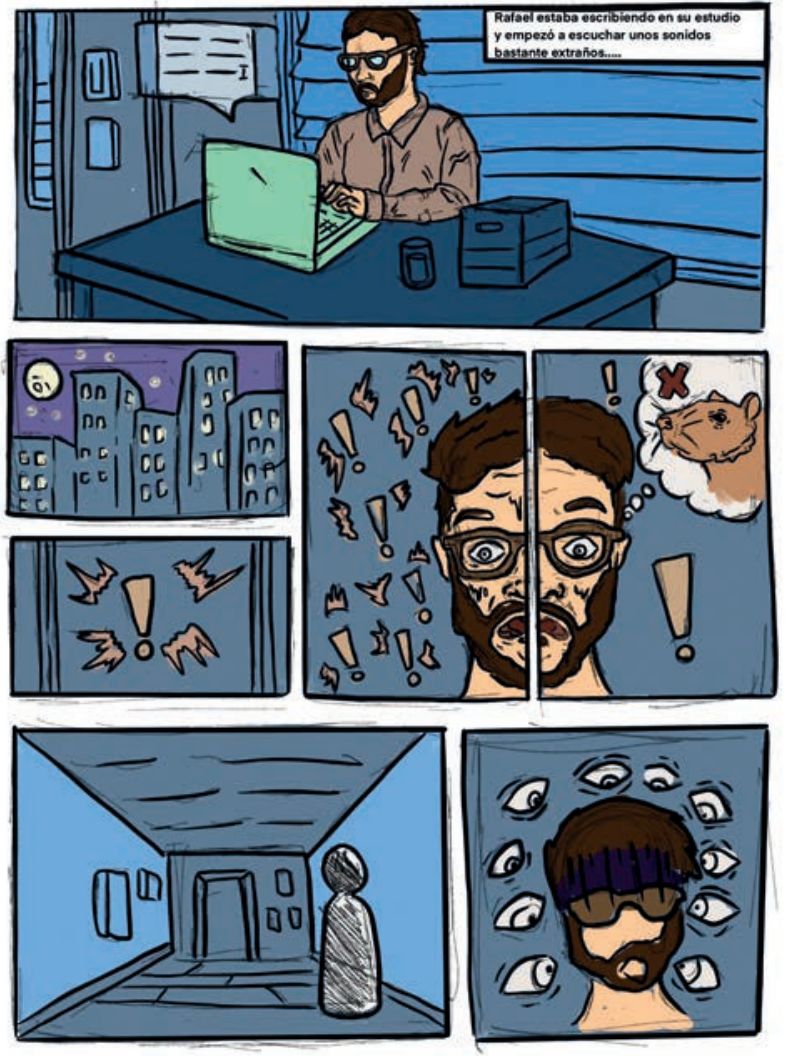

Estos proyectos de cómic, presentados a lo largo de dos años en el espacio académico electivo de narrativa del cómic, evidencian el interés de los jóvenes en contar una historia que los toque, lo que plantea un reto en sus búsquedas narrativas. A través del artículo pudimos verificar los elementos determinantes en la estética de los proyectos analizados. Con este análisis se pueden comprobarlas influencias de los múltiples medios audiovisuales en las diferentes épocas en que el cómic ha sido parte de la historia.

El espacio académico Narrativas del cómic ofrece un método pedagógico para que los estudiantes puedan expresar su preocupación sobre su participación en la actividad social o proponer nuevas ideas en las narrativas de ficción. Los estudiantes logran estos objetivos gracias a reconocerse como parte de un todo, que es el ser jóvenes de la Generación Z, lo cual suscita un interés común como se ha podido comprobar en este ejercicio. Todo esto permite explorar un entorno en el que los jóvenes logran ser los gestores de su mundo, con alternativas lógicas
Figura 10. Se vende en la Coruña (2019-1).

Nota: Se vende en la Coruña es una historia presentada por los estudiantes de Comunicación Social, Erick Giovanny Cano, Juan Manuel González, Felipe Olaya y David Santiago Rodríguez. Fuente: Cano et al. (2019) 
y coherentes a su relación social con el otro a través de un recurso como el cómic, el cual se transforman en un mecanismo que los unifica.

Un interés adicional de este artículo es suscitar en el docente la incursión del cómic al interior del aula como una herra-

Un interés adicional

de este artículo

es suscitar en el

docente la incursión

del cómic al interior

del aula como

una herramienta

pedagógica. mienta pedagógica. A ese respecto, un estudio realizado en el 2015 (Aleixo y Sumner, 2016) pudo comprobar que los estudiantes retienen más información al leer siete páginas cuyos contenidos académicos se han desarrollado a manera de cómic, en comparación con los contenidos desarrollados en un texto académico formal. Los recursos didácticos que permitan la confluencia de medios visuales, textuales y los resultados de esta sinergia permiten una mejor asimilación de conceptos en los diferentes programas universitarios, en especial aquellos que son exigentes en la generación de competencias específicas de los estudiantes universitarios.
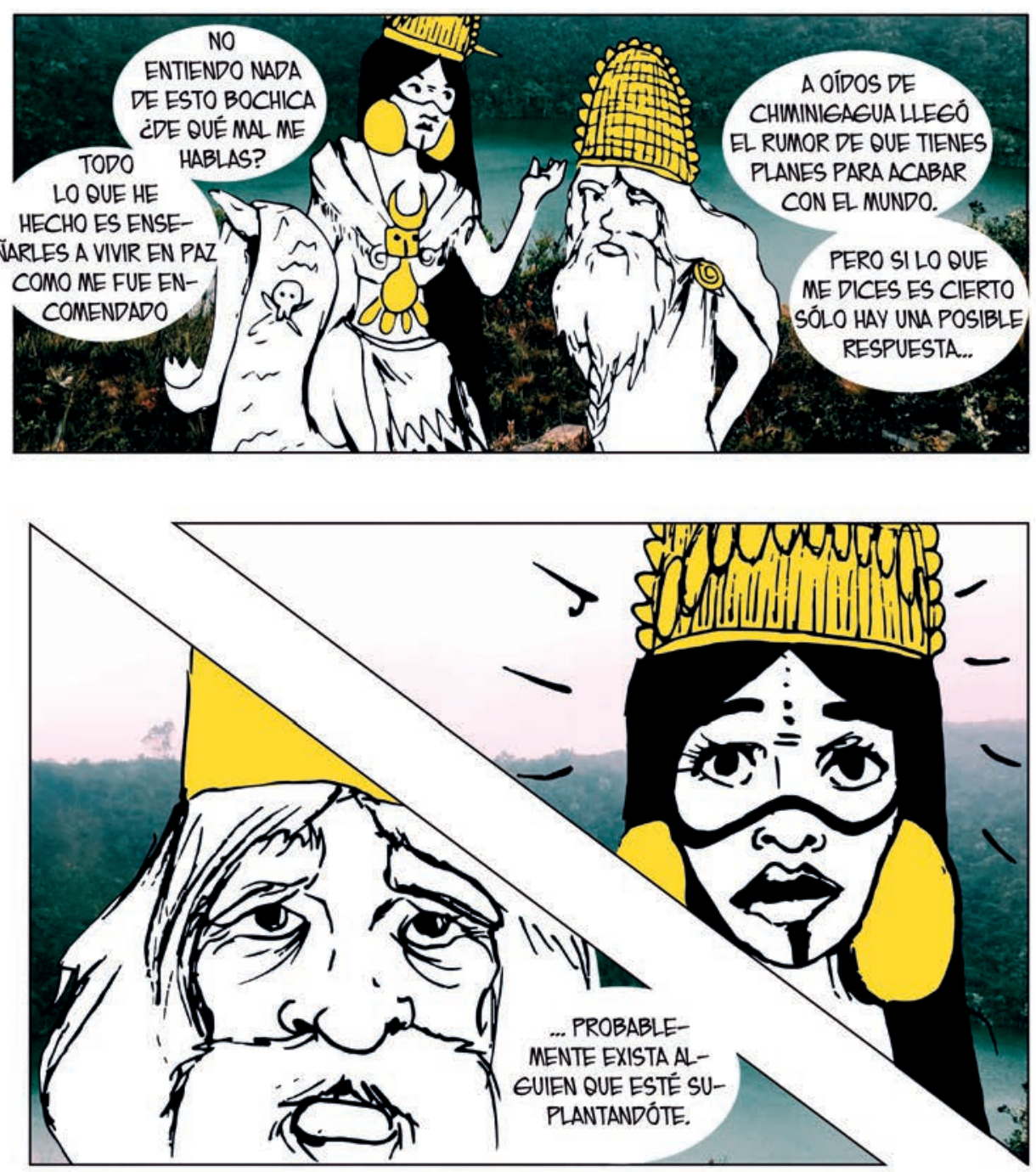

ESTE FUE EL COMIENZO DE UNA TRAVESIA EN LA QUE BACHUÉ TENDRÍA QUE EMBARCARSE, EL BIEN YEL MAL SE ENFRENTABAN Y ESTE ERA SÓLOEL PRIMER PASO. 


\section{R E F E R E N C I A S}

ALEIXO, P. Y SUMNER K. (2017). Memory for Biopsychology Material Presented in Comic Book Format. Journal of Graphic Novels and Comics, 7(1),79-88. https://www.tandfonline.com/doi/abs/10.1080/21504857.2016.1219957

ARBOLEDA BERNAL, S., DONCEL ROBAYO, J. Y RINCón REY, S. (2018). Sin nombre [Manuscrito sin publicar]. Facultad de Diseño Gráfico, Universidad Santo Tomás.

CANO, G. E., GONZÁLEZ, J. M., OLAYA, F., RODRíGUEZ, D. S. (2019). Sevende en la Coruña [Manuscrito sin publicar]. Facultad de Diseño Gráfico, Universidad Santo Tomás.

"CORAJE EL PERRO COBARDE" [Imagen]. descargaserieshoy.blogspot.com. https://descargaserieshoy.blogspot. com/2018/o8/coraje-el-perro-cobarde.html

GAlEANO VÉLEZ, J. A. (2018). Tyrius [Manuscrito sin publicar]. Facultad de Diseño Gráfico, Universidad Santo Tomás.

GAMERO, A. (2018, o2 de mayo). Por qué deberías incluir cómics entre tus lecturas, si es que no lo haces todavía. La piedra de Sísifo. https:/lapiedradesisifo.com/2018/05/02/ por-que-deberias-incluir-comics-entre-tus-lecturas-si-es-que-no-lo-haces-todavia/

GOULD, C. (1931, enero). Dick Tracy [comic]. Chicago Tribune. Heritage Auctions.

"KIM POSSIBLE". [Imagen]. Andtheshowmustgoon.com. https://andtheshowmustgoon. com/2019/08/31/20-tv-cartoons-that-i-use-to-watch/

KELLY, J., BENES, E., DERENiCK, T., ROULEAU, D., KERSCHL, K. Y EAGLESHAM, D. (2006, o6 de abril). The Adventure of Superman, 649. view-comic.com. https:/view-comic.com/adventures-of-superman-1987-issue-649/

"LAS CHICAS SUPORPODEROSAS" [IMAGEN]

"LAS SOMBrías AVENTURAs DE BILly y MANDY" [Imagen]. Fandom.com. https://doblaje.fandom.com/es/wiki/ Las_sombr\%C3\%ADas_aventuras_de_Billy_y_Mandy

LUEN YANG, G. (2018, 10 de enero). The evolution of comic books: From "mentally deficient" to brain boosting. Portal Big Think. https:/bigthink.com/videos/gene-luen-yang-how-comic-books-can-make-kids-and-adults-smarter

MARTíNeZ, N. (2018, 30 de mayo). La generación Z es autodidacta, sensible con el medio a mbiente y adicta a la tecnología. Universitat Oberta de Catalunya. https:/www.uoc.edu/portal/es/news/actualitat/2018/133-generacion-z.html

MOORE, A. Y SWAN, C. (1986, septiembre). Superman: ¿Qué pasó con el hombre del mañana? [comic]. DC Comics.

NúÑ̃E, M., QUICA, R, PAVAJEAU, C. I., SOTO, A. F. Y OLMOS, N. K. (2019). Bachué [Manuscrito sin publicar]. Facultad de Diseño Gráfico, Universidad Santo Tomás.

och○A, J. (2017). Un súper aliado de la lectura: los cómics. Infotecarios. https://www.infotecarios.com/super-aliado-la lectura-los-comics/\#.XviY-WhKiUk.

"PORTADA FINAL FANTASY VII" [IMAGEN]. Everyeye.it. https://wwW.everyeye.it/articoli/recensione-final-fantasy-7remake-ritorno-capolavoro-ps4-48108.html

“PORTADA HALF- LIFE" [imAGEN]. Infobae.com. https://www.infobae.com/esports/2019/11/19/

la-desarrolladora-valve-anuncio-el-regreso-de-la-clasica-franquicia-half-life/

"PORTADA METAL GEAR SOLID" [imagen]. Atomix.vg. https://atomix.vg/

el-primer-metal-gear-solid-regresa-a-la-vida-gracias-a-dreams-de-ps4/

"PORTADA RESIDENT EVIL 2" [IMAGEN]. IGN. https:/es.ign.com/resident-evil-2-remake

"PORTADA The LEGEND Of ZeldA: OCARina on Time". Miracomohacerlo.com. https://miracomohacerlo.com/ descargar-legend-of-zelda-ocarina-of-time-android/

"SAMURÁI JACK" [IMAGEN]. Filmaffinity.com. https://wWw.filmaffinity.com/es/film128519.html

SIEGEL, J. Y SHUSTER, J. (1938, abril). Superman [comic], 1. Action Comics. https:/superman.fandom com/es/wiki/ Action_Comics_Vol.1_1

SHOOTER, J. Y SWAN, C. (1967). "Superman's Race With the Flash". Superman [comic], 199, DC Comics. 